\title{
ИЗВЛЕЧЕНИЕ ОСТАТОЧНОГО СОДЕРЖАНИЯ ВЫСОКОМОЛЕКУЛЯРНЫХ УГЛЕВОДОРОДОВ ПРИ ПРОМЫСЛОВОЙ ПОДГОТОВКЕ ГАЗА
}

\author{
Ишмурзин Абубакир Ахмадуллович', \\ ishmurzin36@mail.ru \\ Махмутов Рустам Афраильевич², \\ r.mahmutov@mail.ru \\ Мияссаров Руслан Фуарисович', \\ m-rus_9090@mail.ru \\ 1 Уфимский государственный нефтяной технический университет, \\ Россия, 450062, г. Уфа, ул. Космонавтов, 1. \\ 2 Уфимский государственный нефтяной технический университет в г. Салават, \\ Россия, 453250, г. Салават, ул. Губкина, 22 Б.
}

\begin{abstract}
Актуальность исследования обусловлена необходимостью повышения эффективности выделения ценных компонентов из природного газа в промысловых условиях. Существующие технологии подготовки газа газоконденсатных месторождений характеризуются низкой степенью извлечения пропан-бутановой и этановой фракций. Известно, что природные газы валанжинских и ачимовских отложений содержат большое количество необходимых для нефтехимической продукции компонентов. Промысловая подготовка природного газа газоконденсатных месторождений обычно базируется на технологии низкотемпературной сепарации, где извлечение жидких углеводородов из потока газа происходит путем снижения температуры дросселированием с последующим разделением газовой и жидкой фаз в самостоятельных сепараторах. Технология имеет низкий КПД и ограничена зависимостью от высоких давлений. Рассматривается вопрос дооснащения установок комплексной подготовки газа малогабаритным высокопроизводительным оборудованием, обеспечивающим глубокое охлаждение среды и одновременное разделение на компоненты.

Цель: теоретическое исследование особенностей высокоскоростных процессов подготовки природного газа, провести численный эксперимент, в ходе которого установить влияние основных параметров оборудования на эффективность отделения высокомолекулярных составляющих от метана.

объекты: установки комплексной подготовки газа газоконденсатных месторождений, среднестатистические значения состава газа, критических параметров и производных величин, которые соответствуют условиям северных месторождений.

Методы: построение математической модели, учитывающей компонентный состав газа, определение распределения температуры, давления, скорости, плотности и числа Маха газа в высокоскоростном сепараторе с разделением на компоненты.

Результаты. Предложена технология получения более низких температур, необходимых для комплексной подготовки газа газоконденсатных месторождений. Она реализована на базе газодинамической высокоскоростной технологии с применением трубки Ранка-Хилша и сопла Лаваля. Установлены расчетные зависимости извлечения пропан-бутановой и этановой фракций от достигаемых низких температур.
\end{abstract}

\section{Ключевые слова:}

Природный газ, степень извлечения фракций, низкотемпературный сепаратор, охлаждение газа, трубка Ранка-Хилша, сопло Лаваля.

\section{Введение}

Попутный нефтяной газ (ПНГ) и природный газ (ПГ), добываемые из недр Земли представляют собой смесь углеводородов метанового ряда. В общем объеме добываемого газа большая часть приходится на метан. Ресурсов использования этана, пропана, бутана и более тяжелых углеводородов значительно больше. Поэтому все газодобывающие страны уделяют большое внимание рациональному целевому использованию данных углеводородов [1, 2].

Находясь в продуктивных пластах газовых месторождений, в зависимости от глубины залегания и термобарических условий, природный газ имеет различный компонентный состав. Обычно с нарастанием глубины и, соответственно, пластового давления изменяется состав газа. Для сеноманского газа характерны глубины 1040-1230 м и содержа- ние метана в пластовом флюиде более $98 \%$. Ачимовские залежи расположены в диапазоне 3370-3800 м, содержание метана в пластовом газе в них составляет менее $80 \%$, а содержание этановой фракции свыше $8 \%$.

В газовой отрасли промысловую подготовку газа газоконденсатных месторождений осуществляют по технологии низкотемпературной сепарации (HTC). Процесс извлечения газового конденсата базируется на снижении температуры потока с последующим разделением газовой и жидкой фаз в самостоятельных сепараторах. Технология имеет низкий КПД и ограничена зависимостью от высоких давлений [3-6]. В качестве источников производства холода используют дроссель, эжектор, турбодетандерный агрегат и другие устройства. Степень извлечения индивидуальных компонентов отражена на рис. 1. 


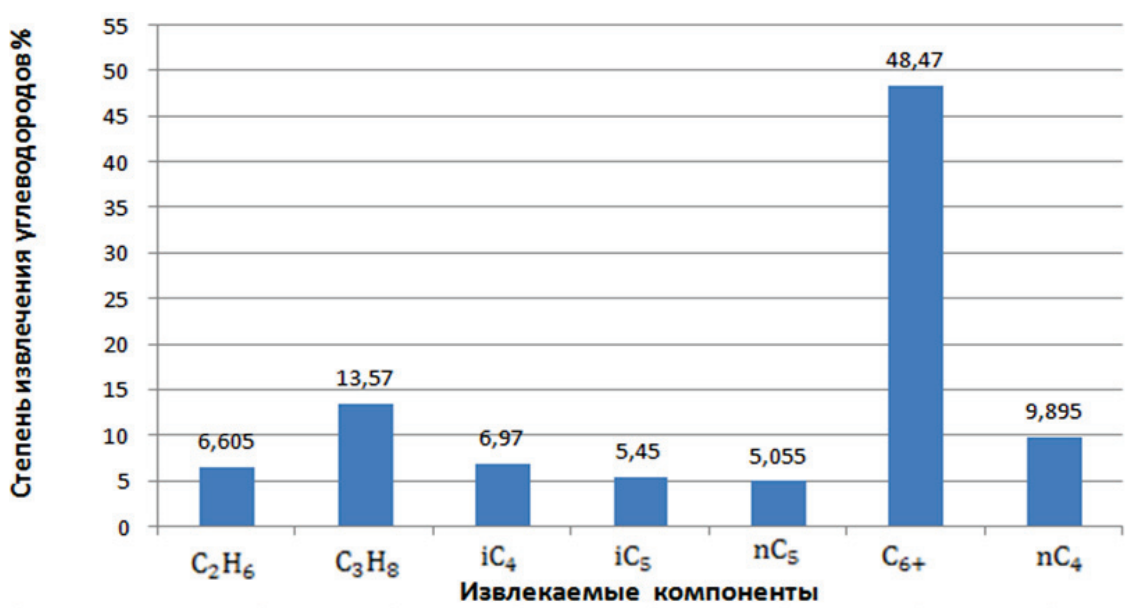

Pис. 1. Степень извлечения индивидуальных компонентов

Fig. 1. Degree of extraction of individual components
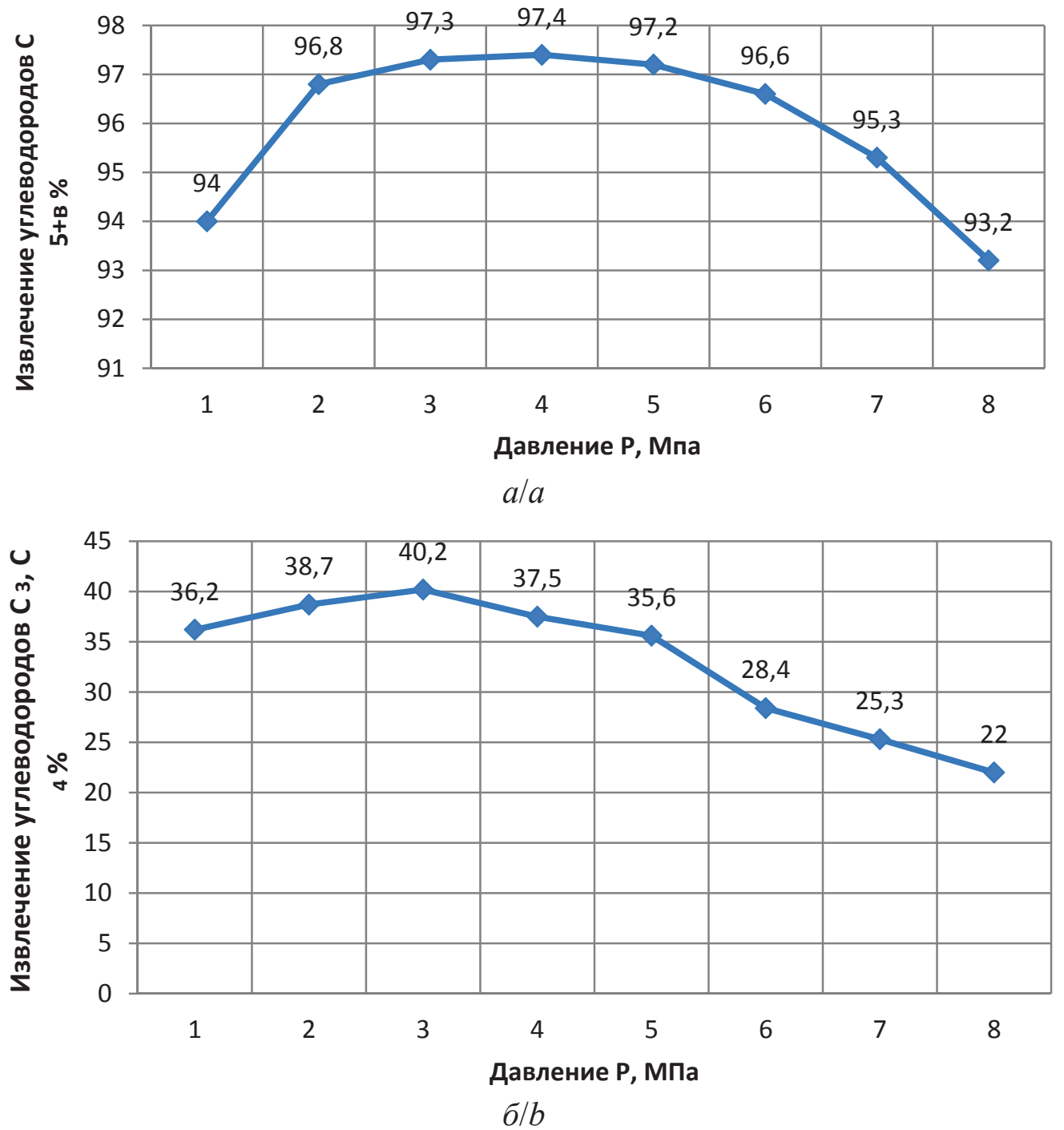

Puс. 2. Зависимость степени извлечения углеводородов: а) $C_{5+}$; б) $C_{3}-C_{4}$, от термобарических параметров

Fig. 2. Dependence of degree of extraction of hydrocarbons: a) $\left.C_{5+} ; b\right) C_{3}-C_{4}$, on thermobaric parameters 
Обеспечение максимального содержания ценных углеводородов, перешедших в жидкую фазу, характеризует әффективность технологической схемы НТС. Степень извлечения углеводородов $\mathrm{C}_{5+}$ и $\mathrm{C}_{3}-\mathrm{C}_{4}$ на температурном уровне минус $30^{\circ} \mathrm{C}$ отражена на рис. $2, a, \sigma$.

Относительно низкий уровень извлечения углеводородов обусловлен температурным уровнем $-30^{\circ} \mathrm{C}$, достигаемым при применении процесса HTC.

\section{Постановка вопроса}

Проведенный анализ различных вариантов низкотемпературной сепарации показал, что достичь полного извлечения углеводородов $\mathrm{C}_{3+}$ возможно лишь на температурном уровне $-90{ }^{\circ} \mathrm{C}$, а этана при данной температуре газоразделения извлекается до 90 \% [6-8]. Для создания столь низких температур необходимо использование внешних холодильных циклов. В настоящее время в низкотемпературных процессах применяются технологические схемы с внешним холодильным циклом, когда в качестве холодопроизводящего элемента используется хладагенты. Холодильная установка представляет собой самостоятельный технологический объект с собственной инфраструктурой, с довольно сложной системой хранения хладагента, что требует значительного увеличения площади промысла. В итоге, если оснастить установки комплексной подготовки газа (УКПГ) северных месторождений таким оборудованием, они превратятся почти в полноценный газоперерабатывающий завод (ГПЗ) и эксплуатация данной установки в условиях промысла сильно усложнится, а стоимость дооснащения достигнет «астрономических цифр» .

Углеводороды, не перешедшие в жидкую фазу на установке НТС, остаются в товарном газе, поступающем в магистральный газопровод. Согласно СТО Газпром 3.1-2-004-2008, эти углеводороды относятся к прямым потерям газодобывающей организации [3]. Обеспечение минимального остаточного содержания в газе высокомолекулярных составляющих является одной из основных задач при разработке технологических схем промысловой подготовки газа уже на стадии предпроектных работ [5].

На сегодняшний день $80 \%$ российского этана производится на Оренбургском гелиевом заводе. Прежде всего перерабатываемый природный газ, а это 15 млрд м ${ }^{3}$ в год, превращается в жидкость с температурой ниже $-100{ }^{\circ} \mathrm{C}$, и затем полученная жидкость подвергается многостадийному разделению, в процессе которого выделяют ценные компоненты. Как показывают исследования, наращивание производства этана - энергозатратный процесс. К примеру, Оренбургский гелиевый завод в год потребляет свыше миллиарда киловатт-часов электроэнергии. Поэтому особую актуальность приобретает разработка технологии достижения низкой температуры относительно небольшой ме- таллоемкости оборудования, которая основана на ресурсо- и энергосбережении.

В пользу глубокой промысловой подготовки ПГ можно привести следующий пример. Один газоконденсатный промысел Ямбургского месторождения дает максимальную производительность 16,5 млрд м $^{3}$ газа в год. Поэтому самый крупный газоперерабатывающий завод России, Оренбургский, просто не в состоянии перерабатывать такое количество газа. По этой причине в России перерабатывается всего 7,5 \% добываемого ПГ, для сравнения - в США в 2015 г. переработано около 90 \% $\Pi \Gamma[4]$.

Все более востребованной становится задача полного извлечения всех целевых продуктов, входящих в состав газа, и их рациональное целевое использование. Существующие УКПГ, базирующиеся на процессе НТС, основанном на охлаждении газа за счет эффекта Джоуля-Томсона или турбодетандере, не отвечают современным требованиям ресурсо- и энергосбережения. Поэтому важной задачей повышения эффективности подготовки природного газа является создание новой технологии, основанной на высокоскоростных газодинамических процессах.

\section{Принципиальная схема охлаждения газа с использованием высокоскоростного газодинамического сепаратора}

Сырой газ от кустов скважин поступает в промысловый сепаратор C-1, где за счет отбойной пластины и действия гравитационных сил из газа отделяется жидкая фаза, которая поступает в разделители Р-1. Далее все компоненты, находящиеся в газообразном состоянии, поступают в теплообменник T-1, где охлаждаются до отрицательной температуры и поступают на вход газодинамического сепаратора (рис. 3). Параметры газового потока, подаваемого на вход, должны обеспечивать требуемые значения ускорения, и рассчитываются исходя из законов газодинамики с учетом геометрии сопла. Далее газовая смесь проходит в сопло и в результате адиабатического расширения начинает охлаждаться и переходить в жидкое состояние.

Под действием центробежных сил образовавшиеся капли прижимаются к стенкам сопла и, достигнув кольцевой щели, попадают внутрь корпуса. Выбор места для отбора жидкой фазы каждого из компонентов на основании указанных соотношений повышает эффективность способа. При этом возможно исключить попадание газовой фазы в приемник с жидкой фазой, если на основании расчетов выполнить ширину щели равной толщине пленки жидкой фазы в данном месте.

Основные отличия данной схемы от схем, использующих клапан Джоуля-Томсона или турбодетандер, состоит в том, что в сверхзвуковом сепараторе происходит охлаждение потока и его разделение на газовую и жидкую составляющие в том же аппарате. Технологические же схемы с использованием клапана Джоуля-Томсона предполагают 


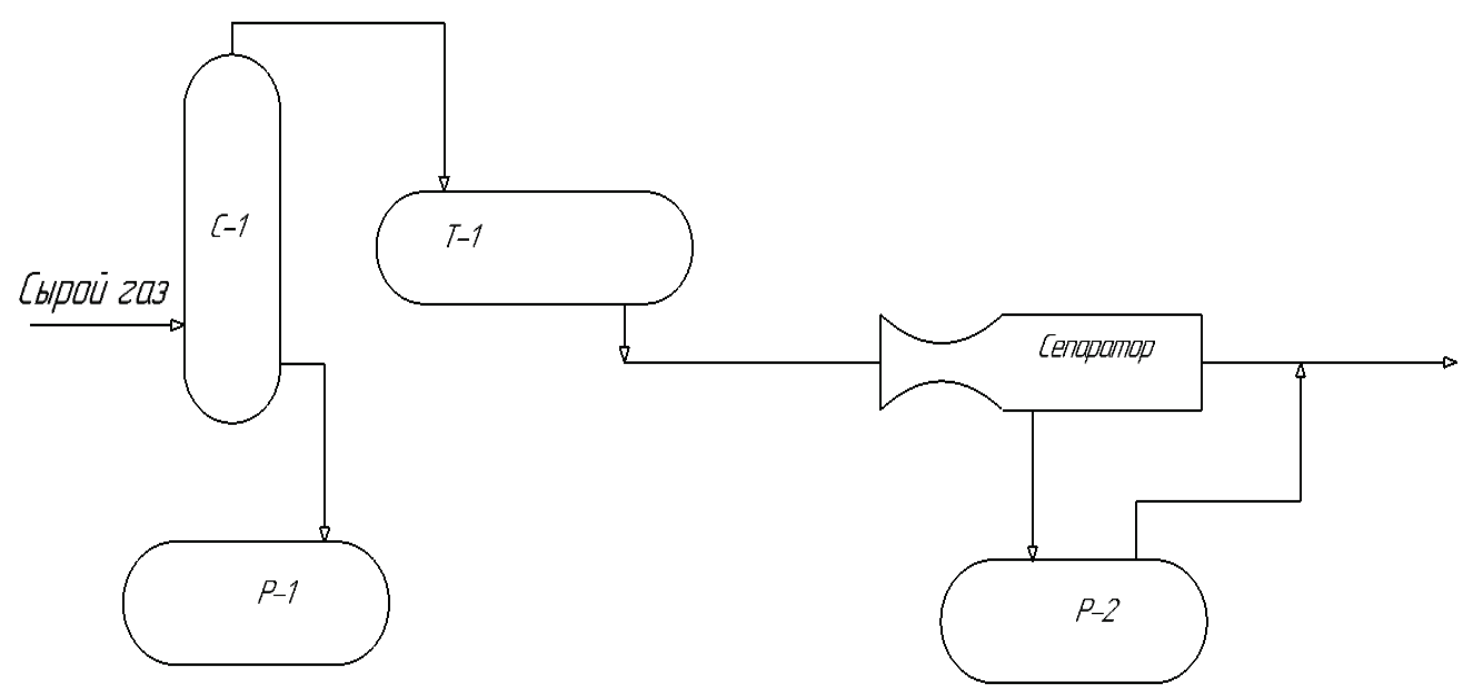

Pис. 3. Схема разделения газов: С-1 - промысловый сепаратор; T-1 - теплообменник; P-1, P-2 - разделители жидкостей

Fig. 3. Gas separation scheme: $C-1$ is the field separator; T-1 is the heat exchanger; $P-1, P-2$ are the liquid delimiters

охлаждение газа и его разделение на двухфазный поток как самостоятельные процессы. Другим важным преимуществом технологии газодинамической сепарации, по сравнению с традиционными технологиями, базирующимися, например, на охлаждении газа при его расширении в дроссельном клапане, является возможность обеспечения более низких температур газа в сверхзвуковом потоке при одном и том же перепаде давлений на выходе из устройств.

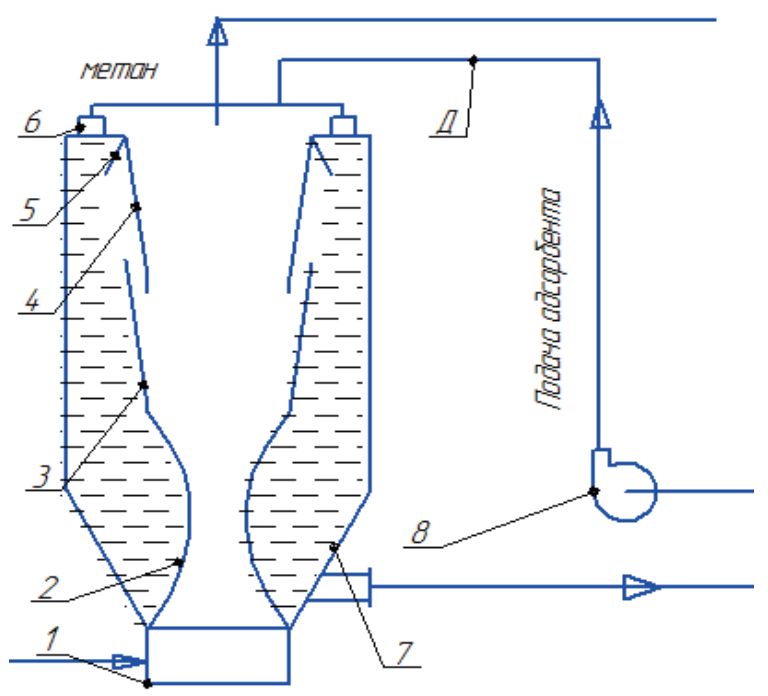

Pис. 4. Установка для извлечения углеводородов в слеси с мета нол: 1 - улитка; 2 - сопло Лаваля; 3 - сепарационная сек иия; 4 - диффузор; 5 - тарелка; 6 - форсунки; 7 - корпус; $8-$ насос

Fig. 4. Installation for extraction of hydrocarbons in mixture with methane: 1 is the snail; 2 is the Laval nozzle; 3 is the separa tion section; 4 is the diffuser; 5 is the plate; 6 are the nozzles; 7 is the body; 8 is the pump

\section{Описание установки охлаждения газа путем совмещения трубки Ранка-Хилша и сопла Лаваля}

Принцип действия основан на создании центробежной силы в аппарате при помощи улитки - 1 , далее закрученный поток газа поступает в конфузорно-диффузорное сопло Лаваля - 2, в котором при адиабатном расширении в дозвуковой части и прохождении критического участка падают его температура и давление, и увеличивается скорость. За счет достижения низкой температуры в сепарационной секции - 3 происходит ослабевание межмолекулярных связей и более тяжелые компоненты отбрасываются к периферии и отбираются посредством кольцевой щели, образованной диффузором - 4 и сепарационной секцией -3 . Далее отделенные углеводороды поступают в межтрубное пространство, куда подается абсорбент через насос -8 , форсунки - 6 и тарелку -5 , для равномерного распределения абсорбента по пространству и выхода насыщенного абсорбента. В качестве абсорбента подобрана смесь нестабильного газового конденсата, это связано с тем, что вещества, близкие по свойствам, хорошо растворяются друг в друге.

Как следует из технологической схемы, охлаждение газа происходит в сопле Лаваля, и одновременно за счет высокоскоростного закручивания происходит температурное разделение на «холодный» и «горячий» потоки. При этом «холодный поток», выработанный в сопле Лаваля, становится более охлажденным за счет передачи своего тепла «горячему потоку». $\mathrm{K}$ тому же за счет закручивания путь движения газа в сопле Лаваля удлиняется и, очевидно, процесс охлаждения газа становится более стабильным. Показатели работы установки близки к характеристикам работы турбодетандера, но при этом увеличивается количество целе- 
вых компонентов, перешедших в жидкую фазу. Это связано с тем, что компоненты, входящие в состав нефтяных и природных газов (этан, пропан и др.), имеют различные температуры конденсации. При понижении температуры газа наступает момент, когда один из компонентов (при его парциальном давлении) начинает конденсироваться. Естественно, что первым сконденсируется компонент, температура конденсации которого при его парциальном давлении в данной смеси максимальна. Если предположить равномерное распределение компонентов в исходной смеси, то вначале выпадут в виде конденсата преимущественно компоненты с максимальным значением нормальной температуры конденсации. Углеводородные газы обладают одной важной особенностью - они растворяются (смешиваются) в углеводородных жидкостях. Поэтому в жидкую фазу переходят не только те компоненты, которые должны конденсироваться при данных значениях температуры и парциального давления, но и другие, даже те, критическая температура которых значительно ниже температуры смеси в данный момент.

Результаты газодинамических расчетов изменения параметров газа по длине сопла Лаваля

Проведенные газодинамические расчеты снижения температуры по длине сопла, изменения скорости, давления потока, числа Маха по длине сопла Лаваля дали результаты, приведенные на рис. 5-8.

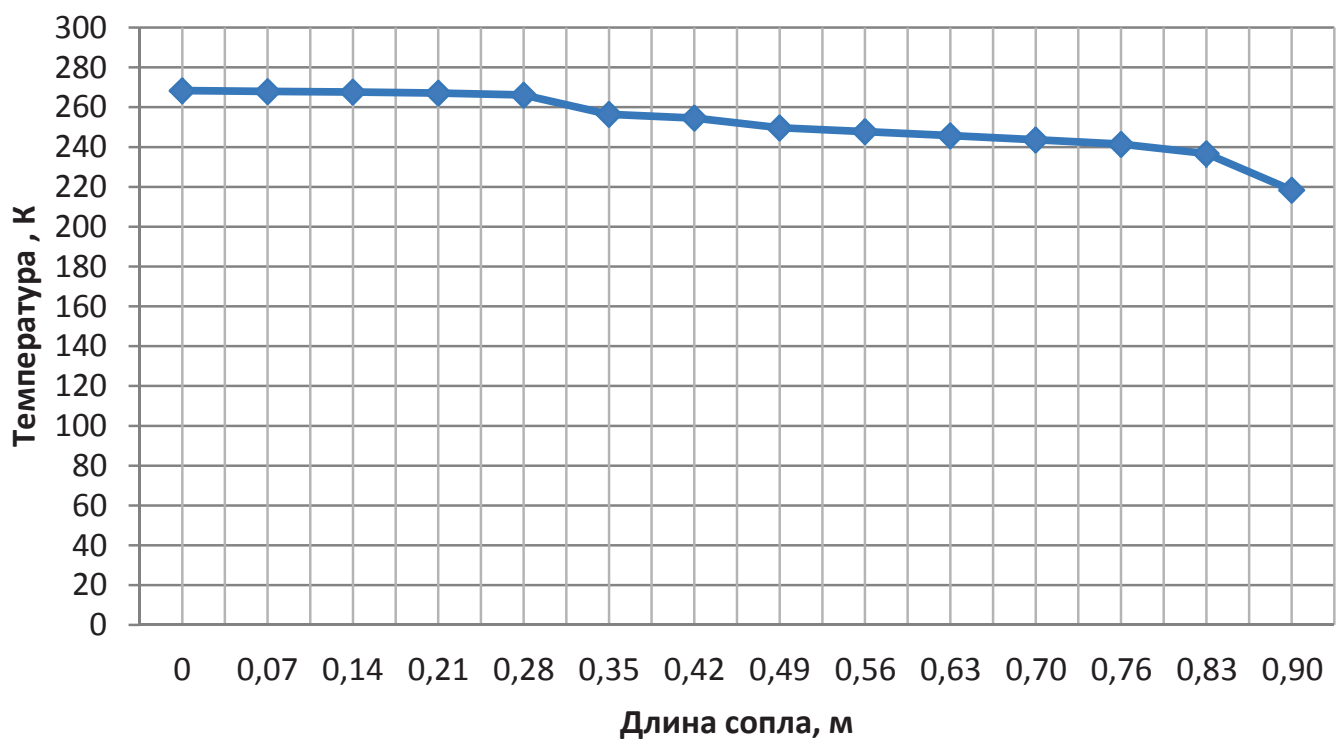

Рис. 5. График изленения телпературы по длине сопла Лаваля

Fig. 5. Graph of temperature change along the Laval nozzle length

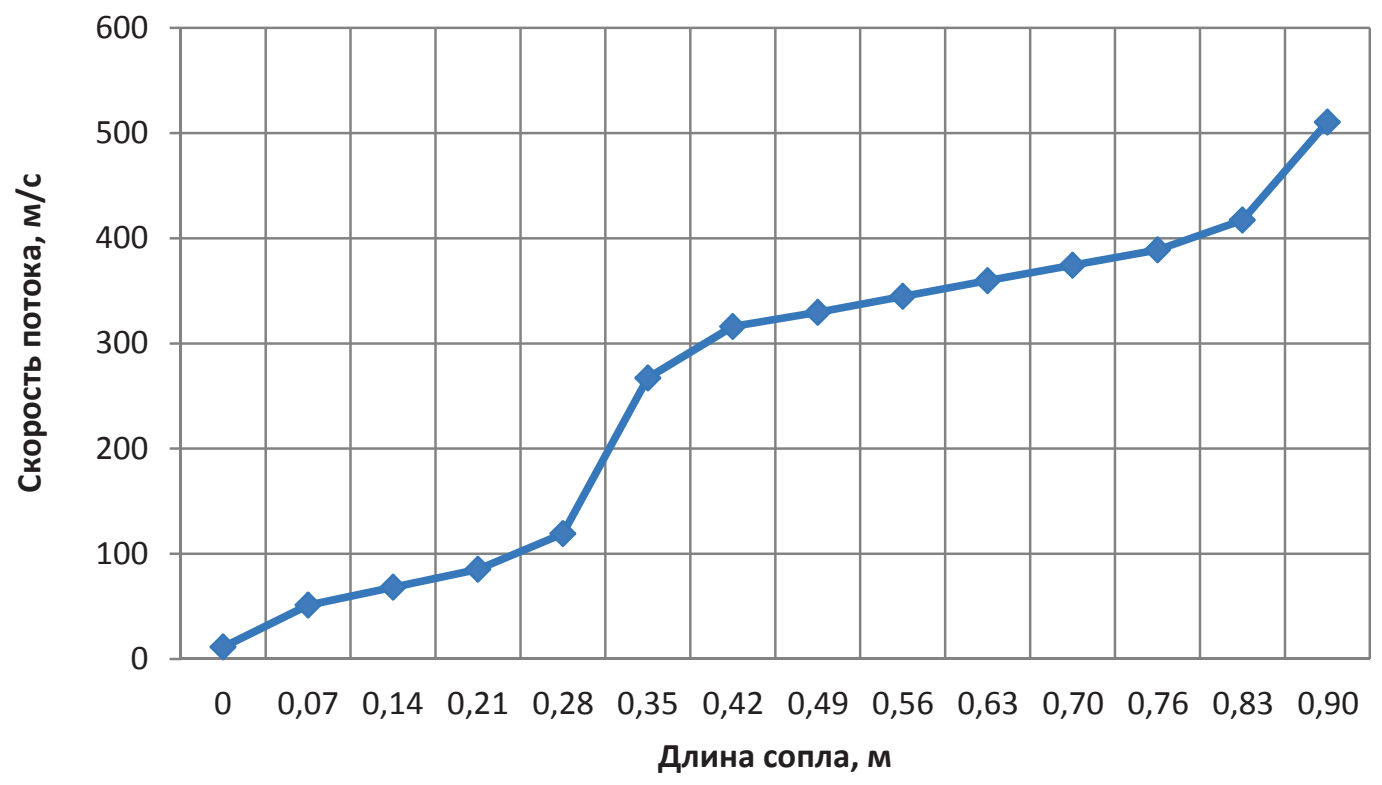

Рис. 6. График изленения скорости по длине сопла Лаваля

Fig. 6. Graph of the velocity change along the Laval nozzle length 


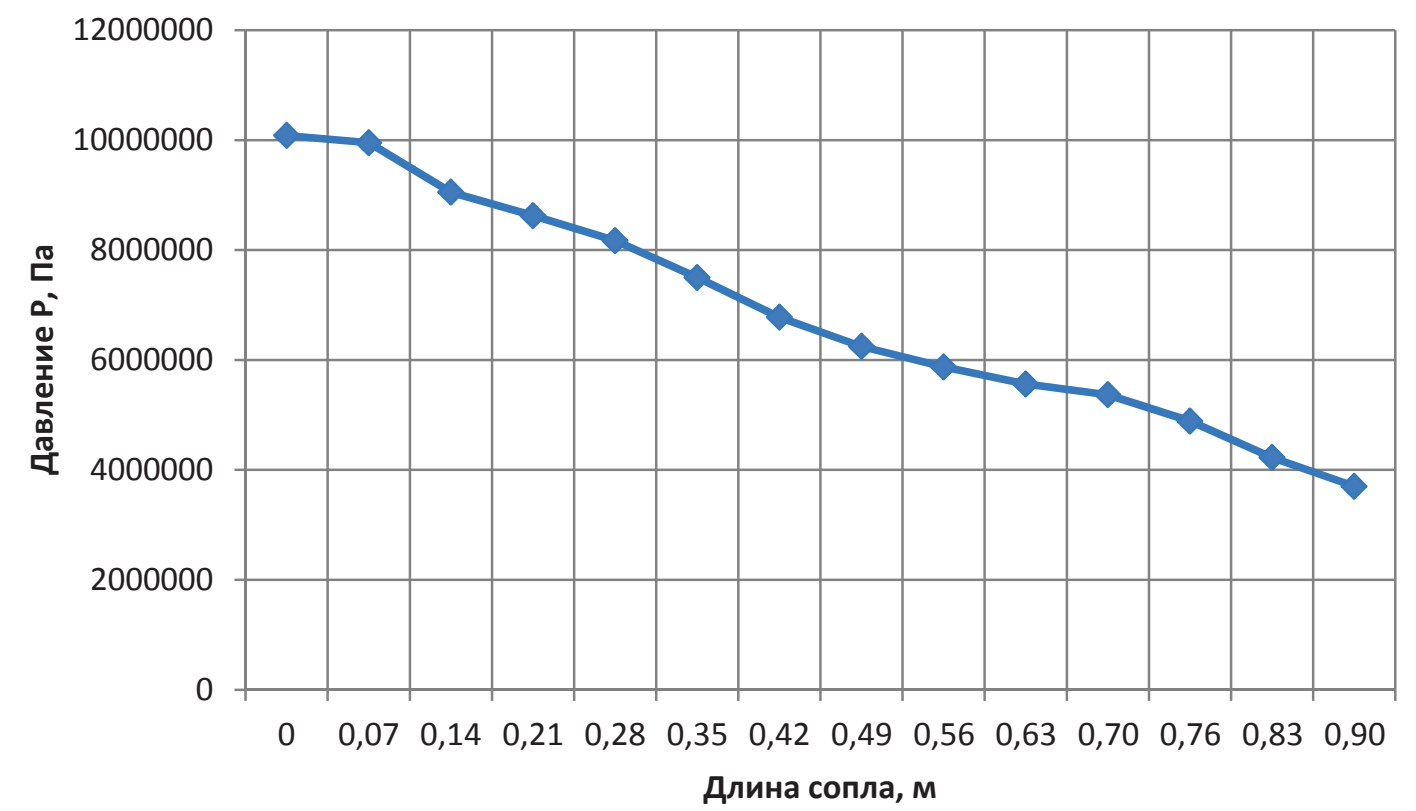

Pис. 7. График изменения давления по длине сопла Лаваля

Fig. 7. Graph of pressure change along the Laval nozzle length

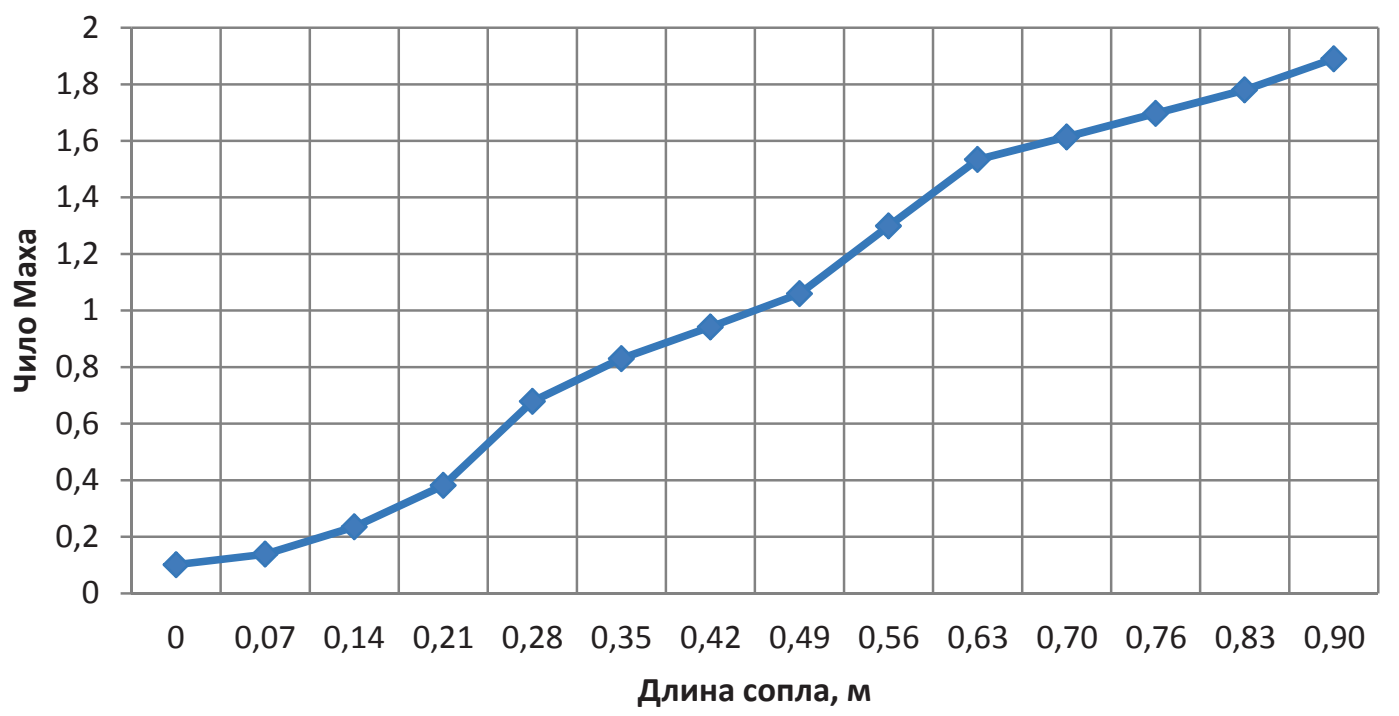

Pис. 8. График изменения числа Маха по длине сопла Лаваля

Fig. 8. Graph of changes in Mach number along the Laval nozzle length

Исходные данные: пропускная способность установки рассчитана на переработку 200 млн $\mathrm{m}^{3}$ газа в год. Показатель адиабаты $k=1,35$ при температуре на устье $T=316 \mathrm{~K}$ при следующем составе газа: $\mathrm{CH}_{4}=93,3 ; \mathrm{C}_{2} \mathrm{H}_{6}=4,22 ; \mathrm{C}_{3} \mathrm{H}_{8}=1,22 ; \mathrm{C}_{4} \mathrm{H}_{10}=0,72$; $\mathrm{C}_{5} \mathrm{H}_{12}=0,15 ; \mathrm{CO}_{2}=0,72 ; \mathrm{N}_{2}=0,54$.

Газодинамический расчет был произведен для природного газа применительно к газоконденсатному месторождению. Течение газа в сопле адиабатное, расширение газа происходит без совершения внешней работы и без теплообмена с внешней средой $[9,10]$. Пропускная способность установки рассчитана на переработку 200 млн м ${ }^{3}$ газа в год.

Изменение температуры по длине сопла связано с созданием перепада давления кратностью 2,7 .
При таком перепаде давления установлена степень извлечения этановой фракции $36 \%$ (рис. 9), степень извлечения пропан-бутанов составила 74 \% (рис. 10).

таблица. Результаты расчета извлекаемой фракиии

Table. $\quad$ Results of calculation of the recoverable fraction

\begin{tabular}{|c|c|c|}
\hline $\begin{array}{c}\text { Целевой } \\
\text { компонент } \\
\text { Target component }\end{array}$ & $\begin{array}{c}\text { Содержание в товарном } \\
\text { газе, млн м } \\
\text { Content in product gas, } \\
\text { million } \text { m }^{3}\end{array}$ & $\begin{array}{c}\text { Извлекаемая часть } \\
\text { фракции, тонн } \\
\text { Recoverable faction } \\
\text { part, tons }\end{array}$ \\
\hline $\begin{array}{c}\text { Этан } \\
\text { Еthane }\end{array}$ & 84400000 & 41,322 \\
\hline $\begin{array}{c}\text { Пропан-Бутан } \\
\text { Propane-Butane }\end{array}$ & 3880000 & 2,017 \\
\hline
\end{tabular}




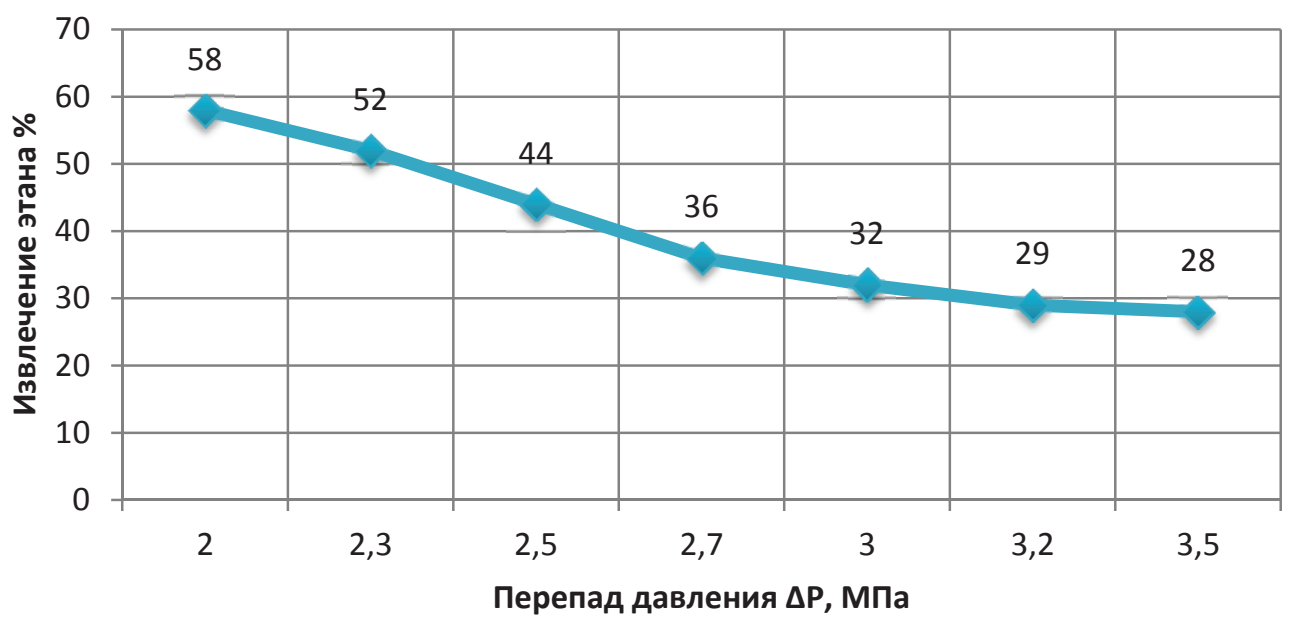

Рис. 9. Зависимость извлечения этановой фракции от перепада давления

Fig. 9. Dependence of ethane fraction extraction on pressure drop

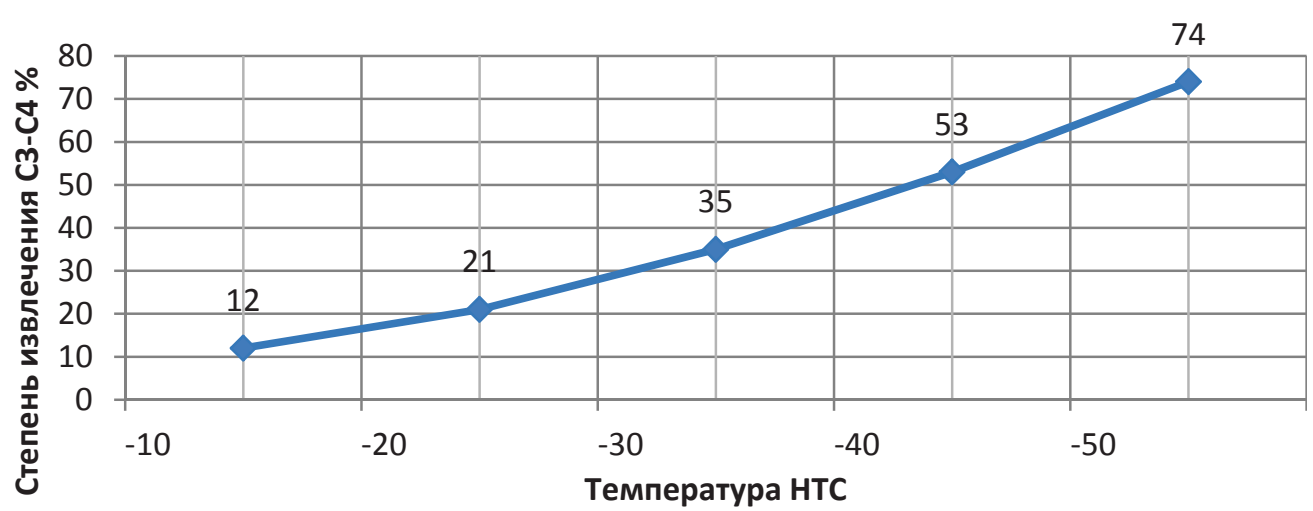

Pис. 10. Степень извлечения пропан-бутановой фракиии

Fig. 10. Degree of extraction of propane-butane fraction

Как видно из вышеприведенных расчетов (таблица), при дооснащении УКПГ валанжинских и ачимовских отложений высокоскоростным газодинамическим оборудованием можно извлекать из газа дополнительно 41 т этана и 2 т пропан бутана, при переработке $200 \mathrm{млн} \mathrm{M}^{3}$ природного газа в год. Если учесть, что один газоконденсатный промысел Ямбургского месторождения дает фактическую максимальную производительность 16,5 млрд $\mathrm{m}^{3}$ газа в год, то количество извлеченного этана составит до 3409 т, а пропан бутана - 161 т в год [6].

Несмотря на наличие значительных перспективных ресурсов, вовлечение этана северных месторождений в нефтехимическую переработку сопряжено с проблемой транспортировки к регионам переработки. Если к затратам на дооснащение УКПГ присовокупить возможные вложения в строительство нового трубопровода для этановой фракции, затраты могут достичь довольно внушительных цифр. По этой причине при переработке до 1 млрд м ${ }^{3}$ газа в год авторами предлагается вариант совместного транспорта насыщенного этаном нестабильного газового конденсата.

В мире широко распространен совместный трубопроводный транспорт нефти и жидкостей с высокой упругостью паров. Совместная перекачка смеси различных продуктов - от сырой нефти до жидкого этана - ведется по трубопроводу диаметром 200 мм и длиной 352 км, связывающему промыслы в северозападной части штата Луизиана (США) и нефтеперерабатывающий завод в районе г. Хьюстона. Общая производительность трубопровода 4,3 тыс. $\mathrm{M}^{3} /$ сут. Кроме того, по пути в магистраль закачивают в одном из пунктов 79,5 $\mathrm{m}^{3} /$ сут этано-пропановой смеси. Хотя упругость паров смеси достигает 1,75 МПа, ее эксплуатация не вызывает затруднений $[11,12]$.

Опираясь на зарубежный опыт, можно утверждать, транспортировка нестабильного конденсата и этановой фракции не вызовет затруднений, упругость насыщенных паров перекачиваемой смеси составит 1,47 МПа, а количество извлеченного этана составит 205 т в год [6].

\section{Заключение}

В статье дано теоретическое обоснование эффективности применения высокоскоростных газодинамических процессов и оборудования для подготовки природного газа газоконденсатных месторождений. Приведены расчеты давления и температуры при совмещении процессов, протекающих 
в трубке Ранка-Хилша и сопла Лаваля, повышающие эффект снижения температуры.

Существующие УКПГ, базирующиеся на процессе низкотемпературной сепарации, основанном на охлаждении газа при падении его давления в дросселе за счет эффекта Джоуля-Томсона с получением температуры охлаждения газа $-30^{\circ} \mathrm{C}$, не отвечают современным требованиям ресурсо- и энергосбережения при эксплуатации месторождений [13-22]. Степень извлечения пропан-бутановых фракций при этом составляет порядка 20 мас. \% , а этан причисляется к категории сухого газа, и по его отделению от метана специальные меры не предусмотрены.

\section{СПИСОК ЛИТЕРАТУРЫ}

1. Мияссаров Р.Ф., Ишмурзин А.А., Махмутов Р.А. Метод извлечения этана в смеси с метаном в промысловых условиях путем совмещения трубки Ранка-Хилша и сопла Лаваля // Территория «НЕФТЕГАЗ». - 2017. - № 5. - С. 44-47.

2. Берлин М.А. «Неудобный попутчик» // Сфера. Нефть и газ. 2013. - № 1. - С. 90-92.

3. Прокопов А.В., Истомин В.А, Федулов Д.М.. Степень извлечения и остаточное содержание углеводородов $\mathrm{C}_{5+\mathrm{B}}$ в газе сепарации газоконденсатных месторождений // НефтеГазоХимия. 2016. - № 2. - C. 64-70.

4. Мияссаров Р.Ф., Ишмурзин А.А., Махмутов Р.А. Увеличение эффективности разделения компонентов природного и попутного нефтяного газа с использованием газодинамических процессов // Инженер-нефтяник. - 2017. - № 2. - С. 64-66.

5. Прокопов А.В., Истомин В.А., Федулов Д.М. Выделение углеводородов $\mathrm{C}_{5+\mathrm{B}}$ из газоконденсатной смеси при промысловой подготовке пластового флюида // Вести газовой науки. 2016. - № 4 (28). - С. 202-206.

6. Мияссаров Р.Ф., Ишмурзин А.А., Махмутов Р.А. Способ выделения из газа этановой фракции и особенности ее транспортировки // Нефтепеработка и нефтехимия. - 2017. - № 8. C. $13-15$.

7. Сбор и промысловая подготовка газа на северных месторождениях России / А.И. Гриценко, В.А. Истомин, А.Н. Кульков, Р.С. Сулейманов. - М.: Недра, 1999. - 473 с.

8. Лапидус А.Л., Голубева И.А., Жагфаров Ф.Г. Первичная переработка углеводородных газов. - М.: РГУ нефти и газа имени И.М. Губкина, 2004. - 246 с.

9. Baker P.S., Rathcamp W.R. Investigations on the Ranque-Hilsh (vortex) tube. - Oak Ridge, Oak Ridge National Laboratory, 1954. $-38 \mathrm{p}$.

10. Дейч М.Е. Техническая газодинамика. - М.: Госэнергоиздат, 1961. -669 c.

11. Трубопроводный транспорт нефти и газа. 2 изд. / Р.А. Алиев, В.Д. Белоусов, А.Г. Немудрое, В.А. Юфин, Е.И. Яковлев. - М.: Недра, 1988. - 368 с.
Как показали расчеты, при высокоскоростном закручивании потока газа можно достичь его охлаждения до температуры -50 ?С, что свидетельствует о возможности более полного извлечения целевых компонентов из газа.

Использованием сверхзвукового сепаратора можно достичь 74 \% извлечения пропан-бутановых фракций, к тому же при этом значительно уменьшив габаритные размеры оборудования низкотемпературной сепарации. Полученный показатель составляет трехкратное превышение извлечения пропан-бутановых фракций к существующему состоянию.

12. Коршак А.А., Нечваль А.М. Проектирование и эксплуатация газонефтепроводов. - СПб.: Недра, 2008. - 488 с.

13. Linderstorm-Lang C.U. Studies on transport of mass and energy in the vortex tube. The significance of the secondary flow and its interaction with the tangential velocity distribution. - Denmark: Riso report, 1971. - $117 \mathrm{p}$.

14. Cockerill T. Ranque-Hilsh vortex tube: Master thesis. - Cambridge, $1995 .-237 \mathrm{p}$.

15. Мияссаров Р.Ф., Ишмурзин А.А., Махмутов Р.А. Оборудование низкотемпературной подготовки природного газа газоконденсатных месторождений // Технологии нефти и газа. 2017. - № 3. - C. 57-61.

16. Jaubert J.-N., Mutelet F. VLE predictions with the Peng-Robinson equation of state and temperature dependent calculated through a group contribution method // Fluid Phase Equilibria. 2004. - № 224. - P. 285-304.

17. Ahlborn B.K., Gordon J.M. The vortex tube as a classic thermodynamic refrigeration cycle // Journal of applied physics. 2000. - V. 88. - № 6. - P. 3645-3653.

18. Gao C. Experimental study on the Ranque-Hilsh vortex tube // PhD Study. - Eindhoven, 2005. - $151 \mathrm{p}$.

19. Fulton C.D. Comments on the vortex tube // J. ASRE Refrigerating Engineering. - 1950. - V. 58. - P. 473-479.

20. Gronner J. Successful experience with vortex tube technology at the cavity storage of RWE Energy // $23^{\text {rd }}$ World Gas Conference. Amsterdam, 2006. - $11 \mathrm{p}$.

21. Liu Xingwei, Liu Zhongliang, Li Yanxia. Investigation on Separation Efficiency in Supersonic Separator with Gas-Droplet Flow Based on DPM Approach / Separation Science and Technology. 2014. - P. 2603-2612.

22. Liu Xingwei, Liu Zhongliang, Li Yanxia. Numerical Study of the High Speed Compressible Flow with Non-Equilibrium Condensation in a Supersonic Separator // Journal of Clean Energy Technologies. - September 2015. - V. 3. - № 5. - P. 360-366.

Поступила 21.05.2018 2.

\section{Информация об авторах}

Иимурзин A.A., доктор технических наук, профессор кафедры машин и оборудования нефтяных и газовых промыслов, Механического факультета Уфимского государственного нефтяного технического университета.

Махмутов P.A., кандидат технических наук, ассистент кафедры оборудования предприятий нефтехимии и нефтепереработки, Факультета машин и аппаратов химических производств филиала Уфимского государственного нефтяного технического университета в г. Салават.

Мияссаров P.Ф., аспирант кафедры технологических машин и оборудования, Механического факультета Уфимского государственного нефтяного технического университета. 


\title{
EXTRACTION OF RESIDUAL CONTENT OF HIGH-MOLECULAR HYDROCARBONS DURING FIELD GAS PREPARATION
}

\author{
Abubakir A. Ishmurzin', \\ ishmurzin36@mail.ru \\ Rustam A. Makhmutov \\ r.mahmutov@mail.ru \\ Ruslan F. Miyassarov', \\ m-rus_9090@mail.ru \\ 1 Ufa State Oil Technical University, \\ 1, Cosmonavtov avenue, Ufa, 450062, Russia. \\ 2 Salavat branch of Ufa State Oil Technical university, \\ 22 b, Gubkin avenue, Salavat, 453250, Russia.
}

\begin{abstract}
The relevance of the study is caused by the need to improve the efficiency of the allocation of valuable components from natural gas in field conditions. The existing gas treatment technologies of gas condensate fields are characterized by a low degree of extraction of propane-butane and ethane fractions. It is known that natural gases of the Valanginian and Achimov deposits contain a large number of components necessary for petrochemical products. Field preparation of natural gas of gas condensate fields is usually based on lowtemperature separation technology, where the extraction of liquid hydrocarbons from gas stream occurs by reducing the temperature by throttling, followed by separation of gas and liquid phases in independent separators. The technology has low efficiency and is limited by dependence on high pressures. The article deals with the issue of retrofitting gas treatment plants with small-sized high-performance equipment that provides deep cooling of the medium and simultaneous separation into components.

The aim of the work is theoretical study of high-speed processes of natural gas preparation, numerical experiment for establishing the influence of the main parameters of the equipment on efficiency of separation of high-molecular components from methane.

Objects: complex gas treatment plants of gas condensate fields, mean values of gas composition, critical parameters and derivative values of which correspond to the conditions of the Northern fields.

Methods: construction of a mathematical model that takes into account gas component composition, determination of distribution of temperature, pressure, velocity, density and the Mach number of gas in a high-speed separator with separation into components.

Results. The authors have proposed the technology of obtaining lower temperatures required for complex gas treatment of gas condensate fields. It is implemented on the basis of gas-dynamic high-speed technology with the use of the Ranque-Hilsh tube and Laval nozzle. The calculated dependences of extraction of propane-butane and ethane fractions on the achieved low temperatures are established.
\end{abstract}

Key words:

Natural gas, degree of extraction of fractions, low-temperature separator, gas cooling, Ranque-Hilsh tube, Laval nozzle.

\section{REFERENCES}

1. Miyasarov R.F., Ishmurzin A.A., Makhmutov R.A. Method of extraction of ethane mixed with methane in field conditions by combining tube of the Wound - hilsa and nozzle Laval. Territoriya «NEFTEGAZ», 2017, no. 5, pp. 44-47. In Rus.

2. Berlin M.A. «Neudobny poputchik» [Uncomfortable fellow traveler»]. Sphere. Oil and gas, 2013, no. 1, pp. 90-92.

3. Prokopov A.V., Istomin V.A., Fedulov D.M. The degree of recovery and residual hydrocarbon in the gas separation of gas condensate fields. Oil and gas chemistry, 2016, no. 2, pp. 64-70. In Rus.

4. Miyasarov R.F., Ishmurzin A.A., Makhmutov R.A. Increasing the efficiency of separation of components of natural and associated petroleum gas with using of gas-dynamic processes. Petroleum engineering, 2017, no. 2, pp. 64-66. In Rus.

5. Prokopov A.V., Istomin V.A., Fedulov D.M. The allocation of hydrocarbons $\mathrm{C}_{5+\mathrm{B}}$ from gas-condensate mixture during the industrial preparation of reservoir fluid. Keep gas science, 2016, no. 4 (28), pp. 202-206. In Rus.

6. Miyasarov R.F., Ishmurzin A.A., Makhmutov R.A. Method of discharge from the gas atenolol fraction and its transport. Oil-refining and petrochemicals, 2017, no. 8, pp. 13-15. In Rus.

7. Gritsenko A.I., Istomin V.A., Kulkova A.N., Suleymanov R.C. Sbor i promyslovaya podgotovka gaza na severnykh mestorozhde niyakh Rossii [Collection and field preparation of gas on the Northern oil fields of Russia]. Moscow, Nedra Publ., 1999. 473 p.

8. Lapidus A.L., Golubeva I.A., Yafarov F.G. Pervichnaya pererabotka uglevodorodnykh gazov [Primary processing of hydrocarbon gases]. Moscow, I.M. Gubkin Russian State University of Oil and Gas Publ., 2004. 246 p.

9. Baker P.S., Rathcamp W.R. Investigations on the Ranque-Hilsh (vortex) tube. Oak Ridge, Oak Ridge National Laboratory, 1954. $38 \mathrm{p}$.

10. Deitch M.E. Tekhnicheskaya gazodinamika [Technical gas dynamics]. Moscow, Gosenergoizdat Publ., 1961. 669 p.

11. Aliev R.A., Belousov V.D., Nemudry G.A., Yufin V.A., Yakovlev I.E. Truboprovodny transport nefti i gaza [Pipeline transportation of oil and gas]. $2^{\text {nd }}$ ed. Moscow, Nedra Publ., 1988. 368 p.

12. Korshak A.A., Nechval A.M. Proektirovanie i ekspluatatsiya gazonefteprovodov [Design and operation of oil and gas pipelines]. St-Petersburg, Nedra Publ., 2008. 488 p.

13. Linderstorm-Lang C.U. Studies on transport of mass and energy in the vortex tube. The significance of the secondary flow and its interaction with the tangential velocity distribution. Denmark, Riso report, $1971.117 \mathrm{p}$.

14. Cockerill T. Ranque-Hilsh vortex tube. Master thesis. Cambridge, 1995. $237 \mathrm{p}$. 
15. Miyasarov R.F., Ishmurzin A.A., Makhmutov R.A. Equipment low-temperature treatment of natural gas gas condensate fields. Technology of oil and gas, 2017, no. 3, pp. 57-61. In Rus.

16. Jaubert J.-N., Mutelet F. VLE predictions with the Peng-Robinson equation of state and temperature dependent calculated through a group contribution method. Fluid Phase Equilibria, 2004, no. 224, pp. 285-304.

17. Ahlborn B.K., Gordon J.M. The vortex tube as a classic thermodynamic refrigeration cycle. Journal of applied physics, 2000, vol. 88, no. 6, pp. 3645-3653.

18. Gao C. Experimental study on the Ranque-Hilsh vortex tube. $\mathrm{PhD}$ Study. Eindhoven, 2005. $151 \mathrm{p}$.

19. Fulton C.D. Comments on the vortex tube. J.ASRE Refrigerating Engineering, 1950, vol. 58, pp. 473-479.

\section{Information about the authors}

Abubakir A. Ishmurzin, Dr. Sc., professor, Ufa State Oil Technical University.

Rustam A. Makhmutov, Cand. Sc, assistant, branch of Ufa State Oil Technical University.

Ruslan F. Miyassarov, postgraduate student, Ufa State Oil Technical University.
20. Gronner J. Successful experience with vortex tube technology at the cavity storage of RWE Energy. $23^{\text {rd }}$ world Gas Conference. Amsterdam, 2006. $11 \mathrm{p}$.

21. Liu Xingwei, Liu Zhongliang, Li Yanxia. Investigation on Separation Efficiency in Supersonic Separator with Gas-Droplet Flow Based on DPM Approach. Separation Science and Technology, 2014, pp. 2603-2612.

22. Liu Xingwei, Liu Zhongliang, Li Yanxia. Numerical Study of the High Speed Compressible Flow with Non-Equilibrium Condensation in a Supersonic Separator. Journal of Clean Energy Technologies, September 2015, vol. 3, no. 5, pp. 360-366.

Received: 21 May 2018. 